\title{
Complex eigenvalue analysis of railway wheel/rail squeal
}

\author{
B.C Goo ${ }^{1} *$, J.C. Kim ${ }^{2}$ \\ ${ }^{I^{*}}$ New Transportation Department, Korea Railroad Research Institute, Uiwang, KOREA \\ ${ }^{2}$ High Speed Train Department, Korea Railroad Research Institute, Uiwang, KOREA \\ "Corresponding Author: e-mail: bcgoo@krri.re.kr, Tel. +82-31-460-5243, Fax.+82-31-460-5031
}

\begin{abstract}
Wheel/rail squeal noise of trains is one of the challenging problems of trains, but a successful model for the squeal problem has not been presented until now. In this study, a new approach was presented to investigate the basic mechanism of the wheel/rail squeal noise, using complex eigenvalue analysis by the finite element method. The positive real parts of the eigenvalues reflect self-exciting instable vibration, which is closely related to the occurrence of squeal noise. The effect of parameters such as friction coefficient, wheel/rail contact position, axle load, etc. on the instable vibration was examined. The instability of the vibration system was sensitive to the stiffness of rail support. In lateral creepage when the adhesion coefficient was less than 0.1 , instable vibration modes did not occur. In longitudinal creepage, when the friction coefficient was high enough, instable vibration modes were generated. Numerical predictions could explain many of the field test results.
\end{abstract}

Keywords: Wheel, Rail, Squeal, Finite element, Complex eigenvalue, Contact.

DOI: http://dx.doi.org/10.4314/ijest.v8i1.1

\section{Introduction}

Squeal noise from wheel/rail and brake disc/pad frictional contact is typical in railways. Several hypotheses have been made and examined to explain the mechanism of squeal noise occurrence. The stick-slip hypothesis is well-known. According to this theory, the decrease of friction coefficient with slippage can generate a negative damping in a structure, which can induce self-exited instable vibration. But Eriksson and Jacobson (2001) showed that under stick-slip conditions, squeal did not occur. According to North (Kinkaid 2003), under constant dynamic friction coefficient two neighbouring stable eigenmodes could converge to an instable mode by varying the parameters of the system. This kind of instability is referred to as flutter instability. Rhee (Rhee et. al, 1989) explained that instable vibration occurs by a hammering effect due to local defects in the contact area. In recent years, with the rapid progress of computer capabilities and numerical algorithms, many researchers have applied finite element methods to analyze flutter instability in the brake disc/pad (Festjens et. al, 2012; Kang 2012; Brizard et. al, 201, Liu et. al, 2016).

However, for wheel/rail squeal, finite element analysis of the flutter instability has not been performed much. Mostly experimental and theoretical studies have been done. Liu and Meehan (2012) have asserted that wheel squeal noise was due to the negative slope of adhesion coefficient with creepage. They measured adhesion coefficients using a two-disc test rig. But their experimental adhesion coefficients did not decrease in the range of attack angle, $(7-10) \times 10^{-3}$ radians, where sound pressure level increased suddenly. Hsu et al. (2007) measured lateral force as a function of yaw angle (or lateral creepage). The uncertainty in adhesion coefficient was $\pm 14 \%$. When the adhesion coefficient increased, squeal occurred. Glocker et al. (2009) studied wheel/rail squeal noise by multibody simulation of a rail car running on rigid rails. The car consisted of two bogies and a body. According to them, the influence of friction curve on the stability of the car was minor. Natural vibration modes of the free wheel were more relevant to their measured squeal frequencies. De Beer et al. (2003), using a scale test rig, found that generation of squeal depended on the lateral contact position of a wheel tread. Monk-Steel et al. (2006) showed that longitudinal creepage added to the 
lateral creepage could influence squeal. Heckl et al. (Heckl and Abrahams, 2000; Heckl 2000, Heckl and Huang, 2000) applied the Green's function to analyze stability of a wheel/rail model. They assumed negative slope of creepage curve. They showed that squeal could be controlled by an active control. To attenuate squeal noise, Brunel et al. (2006) installed a metallic ring in grooves in a wheel. They asserted that noise reduction of $10 \mathrm{~dB}$ was measured. To analyze the complex eigenvalues of wheel/rail contact problem by finite element method, Chen et al. (2008) used spring elements to model the contact between wheel and rail. They showed that friction coefficient, contact position, and rail support stiffness had a strong influence on the instability of the wheel/rail system.

In this study, flutter instability was assumed to be the cause of the wheel/rail squeal. To estimate the instability of the wheel/rail system, traditional complex eigenvalue analysis by finite element was used. To consider the real contact between wheel and rail, the three dimensional contact between wheel and rail was analyzed. A modelling method for wheel/rail squeal was proposed and the effect of parameters such as friction coefficient, wheel/rail contact position, axle load, etc. on unstable vibration was examined.

\section{Squeal Noise Tests}

Figure 1 shows the schematic diagram of the squeal noise field test. Four microphones were installed at a height of $1.6 \mathrm{~m}$ from the ground at 0.5 and $2.5 \mathrm{~m}$ from the outer rail. Four three-axis accelerometers were attached on the side of the rails. The radius of the curvature of the track was $150 \mathrm{~m}$, and cant deficiency was zero. The track was ballasted and concrete sleepers were installed. Squeal noise and acceleration of the rails were measured in a depot in Seoul when a subway train was running back and forth at a speed of 20, 25 and $30 \mathrm{~km} / \mathrm{h}$. Figs. 2-4 present the sound spectrum from the microphones at $0.5 \mathrm{~m}$ from the inner and outer rail.

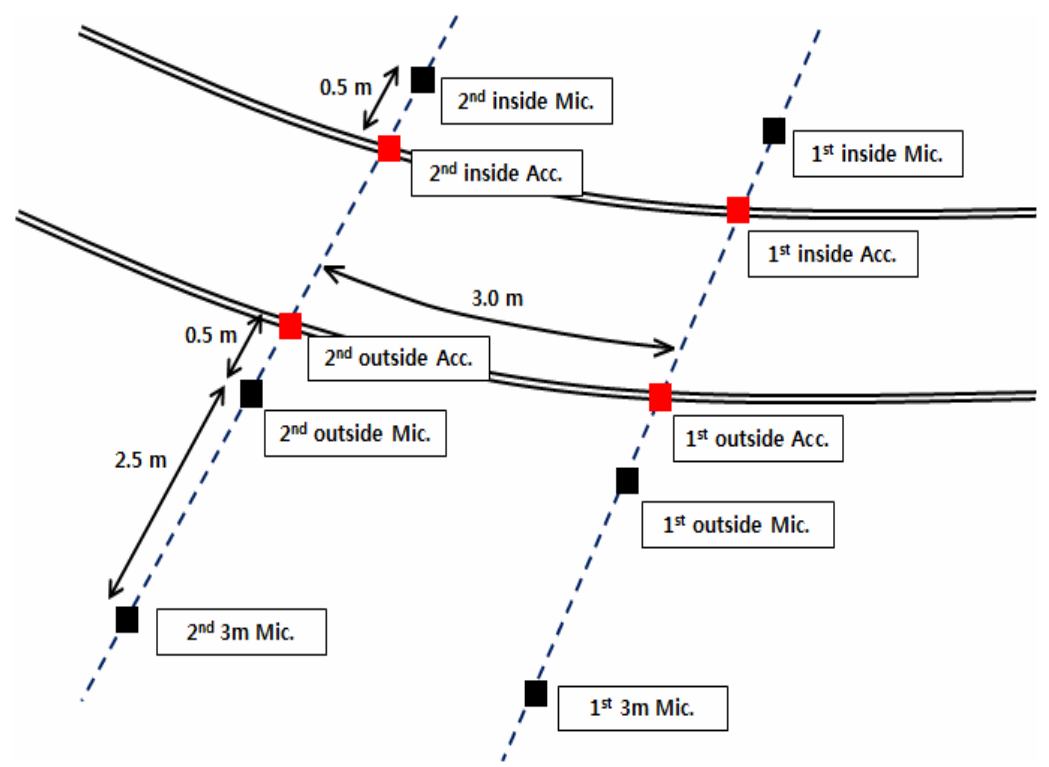

Figure 1. Locations of accelerometers and microphones in the field test.

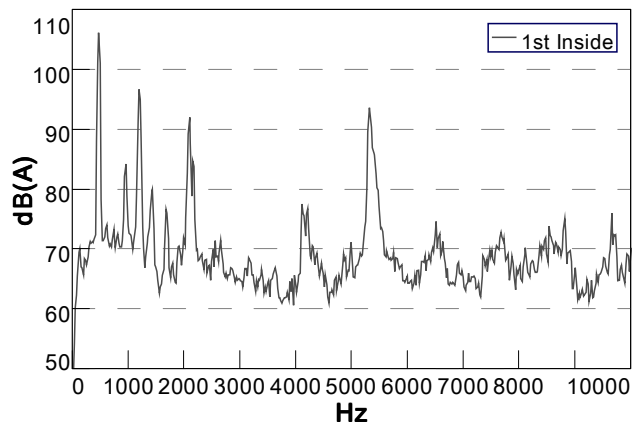

(a)

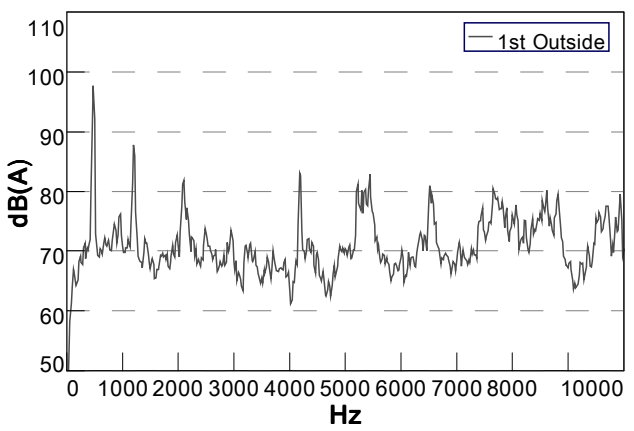

(b)

Figure 2. Squeal noise of a subway train running from left to right at $20 \mathrm{~km} / \mathrm{h}$. 


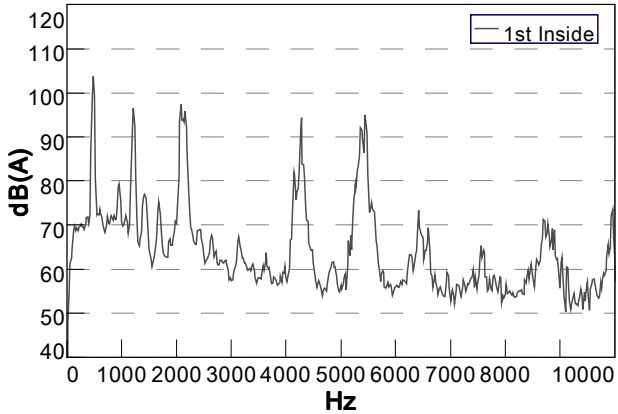

(a)

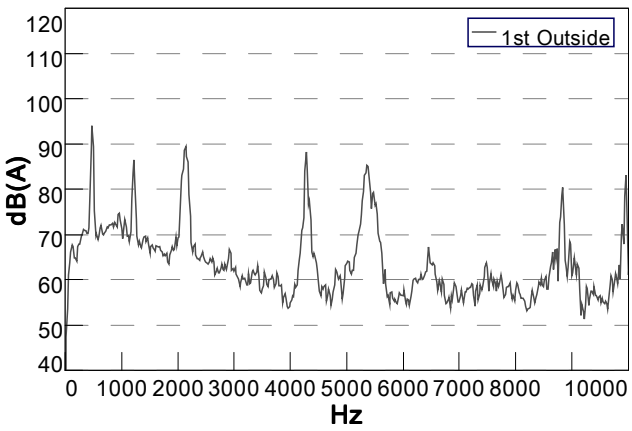

(b)

Figure 3. Squeal noise of a subway train running from left to right at $25 \mathrm{~km} / \mathrm{h}$.

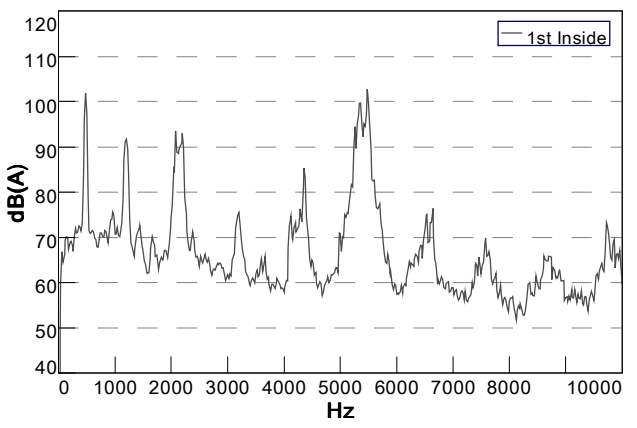

(a)

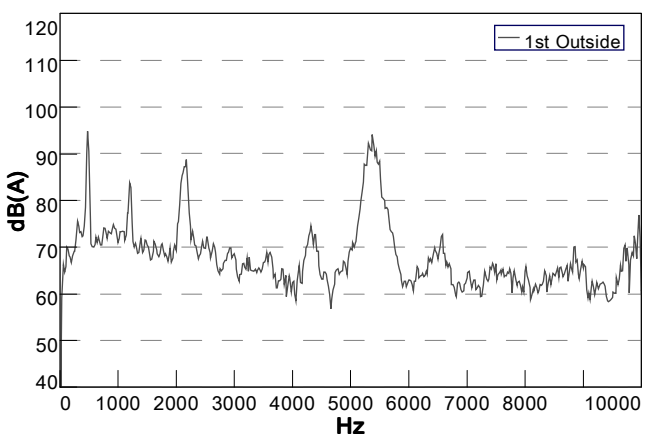

(b)

Figure 4. Squeal noise of a subway train running from left to right at $30 \mathrm{~km} / \mathrm{h}$.

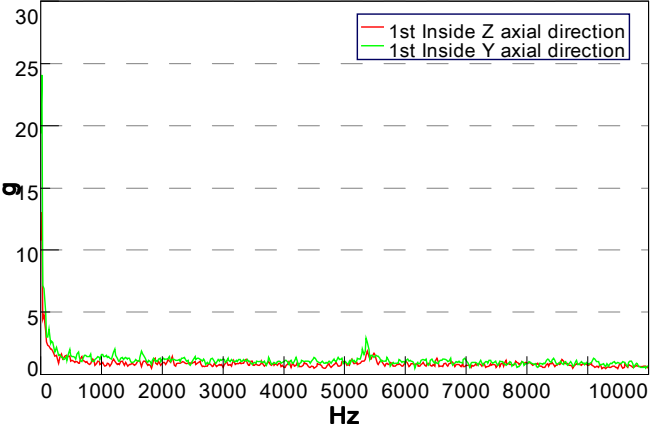

(a)

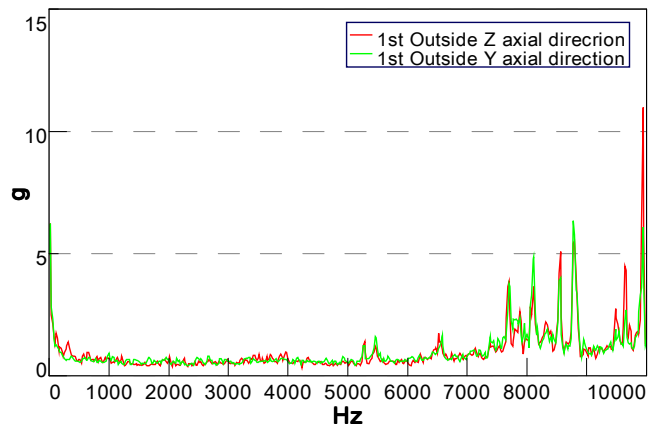

(b)

Figure 5. Acceleration of the rail when the train was running from left to right at $20 \mathrm{~km} / \mathrm{h}$.

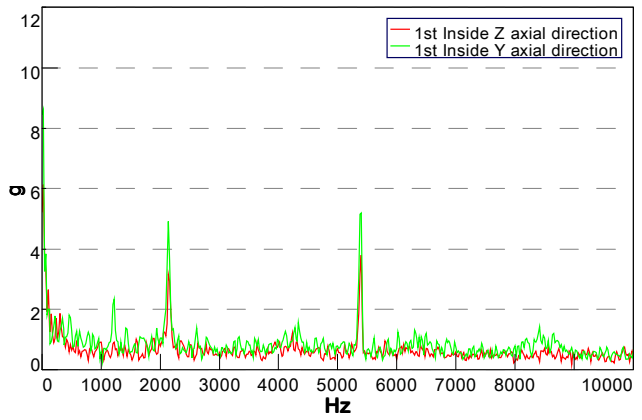

(a)

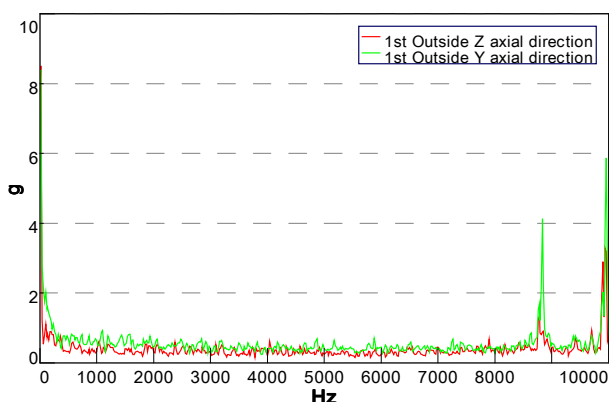

(b) 
Figure 6. Acceleration of the rail when the train was running from left to right at $25 \mathrm{~km} / \mathrm{h}$.

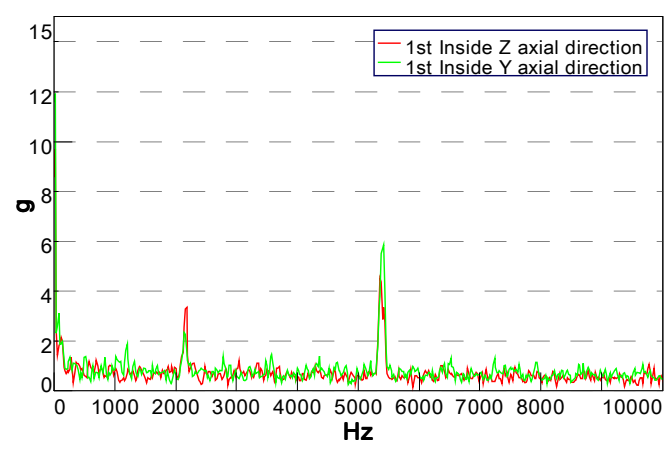

(a)

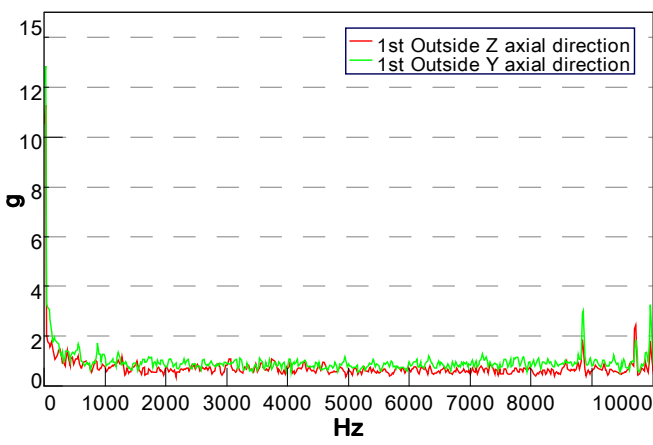

(b)

Figure 7. Acceleration of the rail when the train was running from left to right at $30 \mathrm{~km} / \mathrm{h}$.

The natural frequencies where the sound level is above $80 \mathrm{~dB}(\mathrm{~A})$ are 480, 1220, 2200, 4340, 5420, 8860, 9640 , and 9960 Hz. The sound at $480 \mathrm{~Hz}$ was noise stemming from vibrations of the bogie parts. Figs. 5-7 show the lateral and vertical accelerations of the rails. High accelerations occurred at the frequencies, 2200, 5420, 8860, and $9960 \mathrm{~Hz}$. With a running speed of $20 \mathrm{~km} / \mathrm{h}$, several vibration modes were measured in frequency range, 7500-10000 Hz. At $1220 \mathrm{~Hz}$, a loud squeal noise occurred, but a high vibration mode of the rail was not observed. Therefore, we can deduce that the squeal at $1220 \mathrm{~Hz}$ was due to the vibration of the wheels. The measured results will be compared with numerical results in the following section.

\section{Finite Element Modelling}

3.1 Procedure of the squeal analysis by finite element: Finite element models for squeal analysis are found in the literature (Chen et al., 2008; Brizard et. al, 2011; Sinou et al., 2013). Here, basic concepts and analysis procedure are described. The equation of motion is

$$
[M]\{[C]\{L \&+[K]\{u\}=\{F\}
$$

where $[M],[C]$, and $[K]$ are the mass, damping and stiffness matrices, respectively. $\{u\}$ is the generalized displacement vector, and $\{F\}$ is the force vector. In the wheel/rail contact problem, friction force at the wheel-rail interface is assumed to be

the main cause of generated vibration. The friction force is modelled as a function of displacements of the two contacting materials, and contact stiffness in the contact area:

$$
\{F\}=\left[K_{f}\right]\{u\}
$$

where $\left[K_{f}\right]$ is the friction stiffness matrix which is asymmetric.

Substituting Eq. (2) into Eq. (1), the equation of motion for a friction-induced vibration system is

$$
[M]\left\{[ C ] \left\{1 \&+\left[K-K_{f}\right]\{u\}=\{0\}\right.\right.
$$

where $\left[K-K_{f}\right]$ is not symmetric because $\left[K_{f}\right]$ is asymmetric.

The eigenvalue problem corresponding to Eq. (3) is expressed as:

$$
\left(\lambda^{2}[M]+\lambda[C]+\left[K-K_{f}\right]\right)\{y\}=\{0\}
$$


where $\lambda$ is the eigenvalue. $\{y\}$ is the eigenvector. In general, Eq. (4) has complex eigenvalues. The real part is the damping coefficient. The imaginary part is the natural frequency of the sinusoidal motion. When the real parts of the eigenvalues are positive, the system is instable. The instable modes are prone to generate squeal noise. Hence solving the eigenvalue problem gives us good information on the squeal propensity of a system. But it is not easy to directly solve an eigenvalue problem with an asymmetric matrix. It is common to solve the problem using the subspace projection method. In this study all analyses were carried out in ABAQUS Code, which provides a module to solve complex eigenvalue problems. The procedure of obtaining the complex eigenvalues is as follows:

1) Wheel/rail contact analysis under axle loading without considering friction between wheel and rail.

2) Taking the solution of the first step as initial values, perform friction analysis by the wheel slippage.

3) Find eigenvalues of the system without considering the damping and friction.

4) Finally find complex eigenvalues for a friction-induced vibration system using the eigenmodes in the previous step as a projection subspace.

In the absence of damping and friction terms, Eq. (4) reduces to

$$
\left(\lambda^{2}[M]+[K]\right)\{z\}=\{0\}
$$

where $\{z\}$ is the eigenvector. The Lanczos iteration method was used to solve the symmetric eigenvalue problem. Projecting the matrix $[M],[C]$ and $[K]$ into the subspace of the eigenvectors, $\{z\}_{i}(i=1 \ldots n)$, new matrices $[M *],\left[C^{*}\right]$, and $\left[K^{*}\right]$ are obtained.

$$
\begin{aligned}
& {\left[M^{*}\right]=\left[\{z\}_{1},\{z\}_{2}, \ldots,\{z\}_{n}\right]^{T}[M]\left[\{z\}_{1},\{z\}_{2}, \ldots,\{z\}_{n}\right]} \\
& {\left[C^{*}\right]=\left[\{z\}_{1},\{z\}_{2}, \ldots,\{z\}_{n}\right]^{T}[C]\left[\{z\}_{1},\{z\}_{2}, \ldots,\{z\}_{n}\right]} \\
& {\left[K^{*}\right]=\left[\{z\}_{1},\{z\}_{2}, \ldots,\{z\}_{n}\right]^{T}\left[K-K_{f}\right]\left[\{z\}_{1},\{z\}_{2}, \ldots,\{z\}_{n}\right]}
\end{aligned}
$$

where the superscript, $T$, means the transpose of the matrix.

Thus, Eq. (1) becomes.

$$
\left(\lambda^{2}\left[M^{*}\right]+\lambda\left[C^{*}\right]+\left[K^{*}\right]\right)\left\{y^{*}\right\}=\{0\}
$$

Solving for eigenvalue $\lambda$ and eigenvector $\left\{y^{*}\right\}$ for this reduced problem, we can get the k-th eigenvector $\{y\}_{k}$ of the original eigenproblem.

$$
\{y\}_{k}=\left[\{z\}_{1},\{z\}_{2}, \ldots,\{z\}_{n}\right]\left\{y^{*}\right\}_{k}
$$

3.2 Finite element modeling: Figure 8 shows the cut view of the wheel and rail. They are used in subway trains in Korea. The configurations are very similar to those of UIC Code. The wheel tread has a 1:40 slope. The model in Figure 9 is similar to the model used in (Goo, 2014), where an approach for wheel/rail squeal analysis by finite element was proposed and some numerical results under lateral creepage were presented. In this study, squeal noise test results were added, and finite element analysis under various longitudinal and lateral creepage were carried out and compared with experimental results. For simplicity of modeling, all components installed on the axle except the wheels were neglected. When analyzing the dynamic characteristics of a wheel/rail system, it is difficult to model long rails properly. A $25 \mathrm{~m}$ long piece of rail is welded to another rail to make a longer rail, which is laid on the sleepers in the track. The rails are fastened to the sleepers by fasteners at the interval of about $500 \mathrm{~mm}$. Dynamic behavior of a car and wheelsets depends on the characteristics of rails.

For wheel/rail squeal analysis by finite element, it is difficult to model the long rails of real size because of analysis cost and time problem. In this study, in consideration of the distance between two neighboring sleepers, a rail of $500 \mathrm{~mm}$ long is included in the model. Both end sections cut from the long rail were supported in three directions by springs, which are intended to give the same stiffness as the stiffness by the neighboring material. Experimental data for optimal spring constants was not found in the literature, so arbitrary several values were applied. In the future, more study is required to find a modeling method of long rails. 
Figure 10 shows the boundary conditions on the rail support. Displacements in the x-direction were fixed in two locations, and displacement in the y-direction were fixed in the right end bottom. Besides the boundary conditions, the wheelset and rails were restrained by springs. The connection between the wheelset and the axle box was modelled by springs $\left(K_{x-a}, K_{y-a}\right.$ in Figure 11(a)). The applied spring constant was $K_{x-a}=K_{y-a}=10^{5} \mathrm{~N} / \mathrm{mm}$. In the vertical direction the wheelset was constrained by the wheel/rail contact only. The vertical load, F, by the car body was applied at the center point of the axle bearing seat on the axle (Figure 11(a)). $6000 \mathrm{~kg}_{\mathrm{f}}$ at both points was applied. As discussed above, to realistically simulate the stiffness of a real long rail installed in the track, the rails were also constrained by springs in both end sections (Figure 11(b)). The bottom face of each rail was supported by 51vertical springs at each end section, and the side face was supported by $115 \mathrm{x}$-, $\mathrm{y}$-directional springs. The static and dynamic behaviour of the wheel/rail depends on the boundary conditions and the constraints by springs. So the analysis was performed for various spring constants. The size of the elements in the contact area was in the range of $0.5-1 \mathrm{~mm}$. Linear tetrahedral elements were used. The number of elements was 314367 for the wheelset, and 63698 for each rail. The properties of the wheel and rail are given in Table 1 .

Table 1. Material properties and finite elements.

\begin{tabular}{|c|c|c|}
\hline Item & Wheelset & Rail \\
\hline Elastic modulus $(\mathrm{GPa})$ & 206 & 206 \\
\hline Poisson ratio & 0.3 & 0.3 \\
\hline Density $\left(\mathrm{g} / \mathrm{Cm}^{3}\right)$ & 7.85 & 7.85 \\
\hline
\end{tabular}
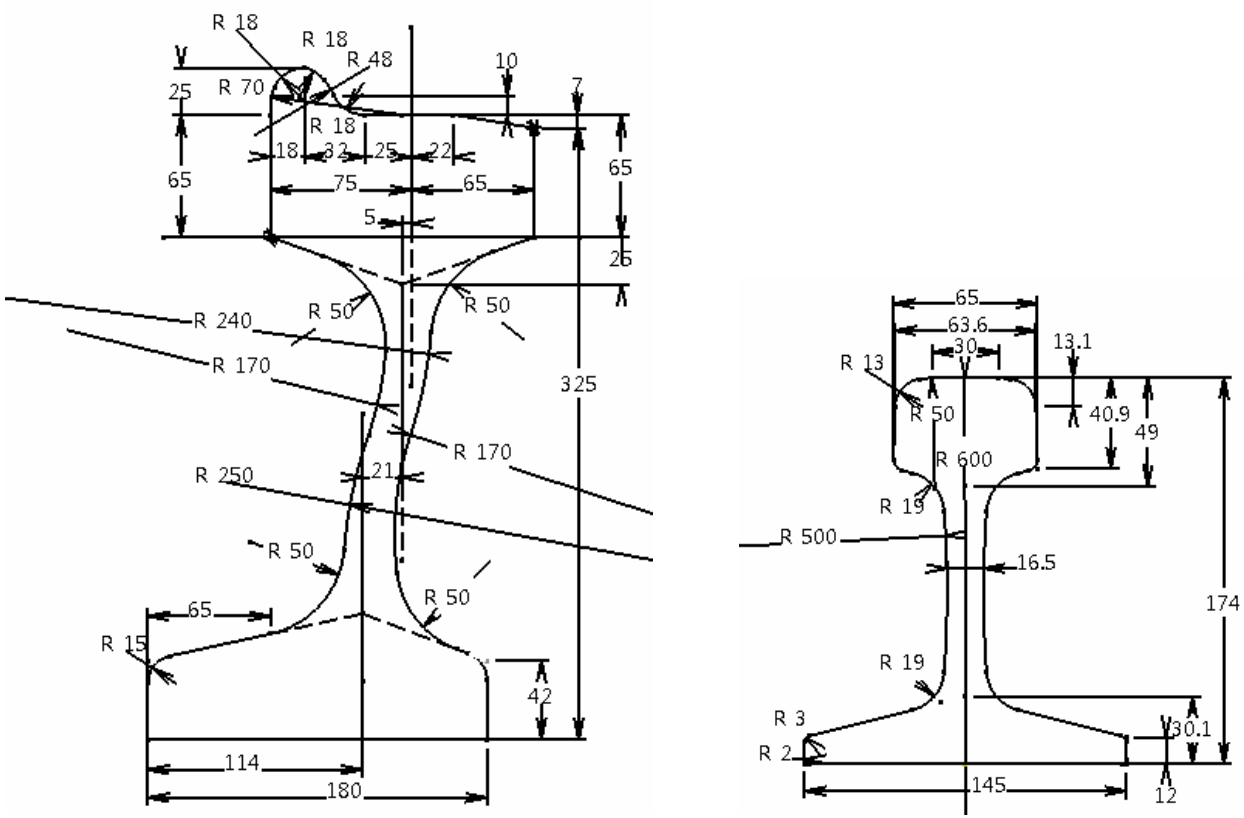

(a) Wheel

(b) Rail

Figure 8. Cut views of the wheel and rail. 


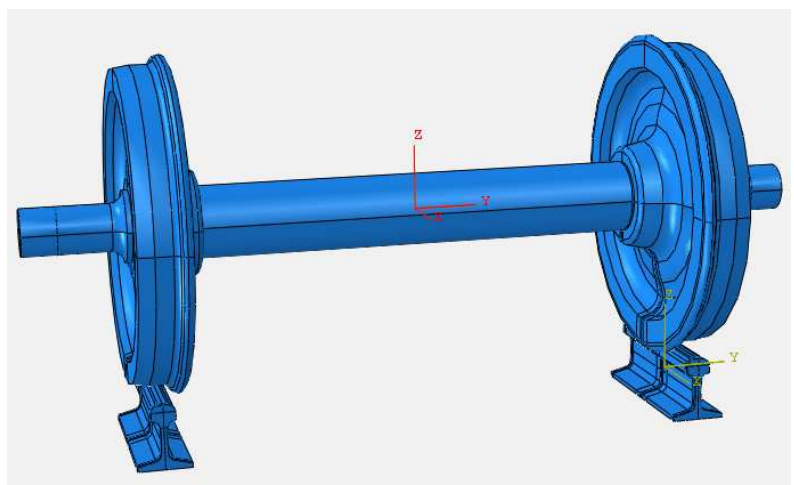

Figure 9. Finite element model of the wheelset and rails.

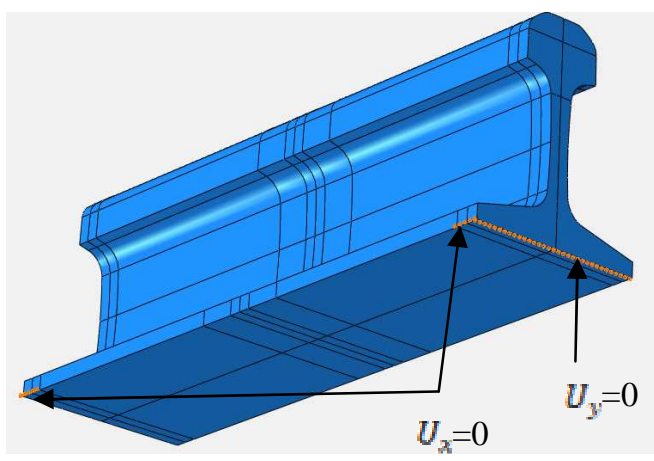

Figure 10. Boundary conditions on the rail.

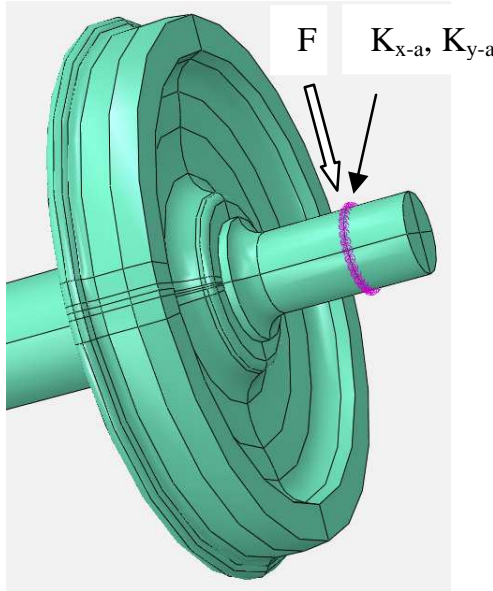

(a) Wheelset

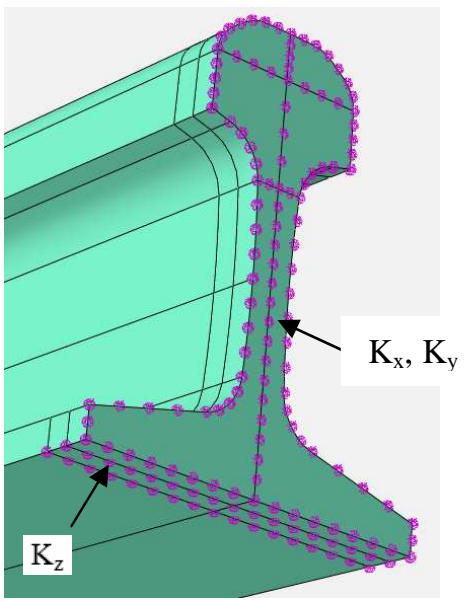

(b) rail

Figure 11. Constrains of the wheelset and rail by springs.

\section{Results and Discussion}

4.1 Squeal by lateral creepage: Figure 12 shows the contact stress distribution when the spring constants on the rail are $K_{x}=K_{y}=1000 \mathrm{~N} / \mathrm{mm}$, and $K_{z}=10000 \mathrm{~N} / \mathrm{mm}$. The friction coefficient between the wheel and rail is $\mu=0.31$. Figure 12 (a) is the von-Mises stress in the contact region under the vertical load only (the aforementioned analysis step 1). It is found that the stress distribution is similar to that of a classical Hertzian contact of two objects. Figure 12(b) shows stress after the frictional force by lateral slippage was additionally applied (analysis step 2). To simulate this frictional contact behaviour, pseudo-movement (refer to ABAQUS manual) of all the nodes of the rail to the positive Y-direction was given at the speed of $5 \mathrm{~m} / \mathrm{s}$. The influence of the 
movement speed was negligible. Because of the frictional load, the area with maximum stress in the wheel moved to the right. In contrast, the high stress field in the rail moved to the left. Figure 13 shows the instable modal shapes.

Two instable modes occurred at frequencies 115 , and $1279 \mathrm{~Hz}$. Figure 14 is the result when $\mu=0.47$ and the same spring constants were applied. In this case three instable modes occurred at 113, 1197, 1278, and $5520 \mathrm{~Hz}$. The vibration mode of the wheel at $1197 \mathrm{~Hz}$ is a combination of in-plane and out-of-plane deformation. At $1278 \mathrm{~Hz}$, the bending mode was dominant. This fact was verified in the field test. A loud squeal occurred at $1220 \mathrm{~Hz}$, but the vibration of the rail was negligible. At $5520 \mathrm{~Hz}$ the vibration of the rail was dominant. In the field test, a high acceleration was measured on the rail at $5420 \mathrm{~Hz}$. Figure 15 shows the results when $K_{x}=K_{y}=10^{4} \mathrm{~N} / \mathrm{mm}, K_{z}=10^{8} \mathrm{~N} / \mathrm{mm}$, and $\mu=0.33$ or 0.35 . New instable modes at 2217,10675 and $11603 \mathrm{~Hz}$ were predicted. At high frequencies, the rail deformation was dominant. In this case the instability of the system was less sensitive to the friction coefficient. In the field test, squeal occurred at $2200 \mathrm{~Hz}$, and a high acceleration of the rail was observed.

In the high frequency band, the acceleration of the rail was large (Figure 5(b)). The predicted results explain the measured results quantitatively. Figure 16 presents two new instable modes at 6916 and $9396 \mathrm{~Hz}$ when $K_{x}=K_{y}=K_{z}=10^{8} \mathrm{~N} / \mathrm{mm}, \mu=0.31$, or 0.35 .

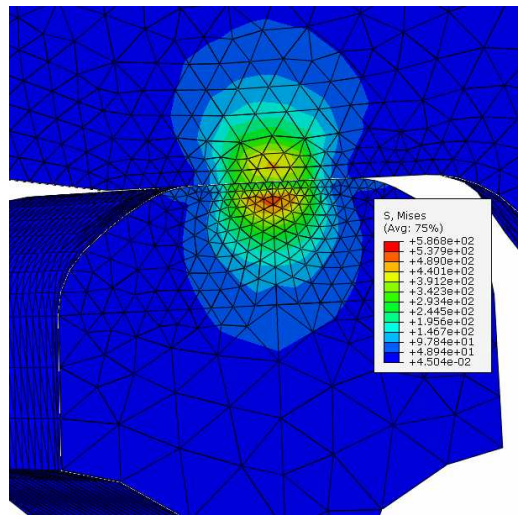

(a) Vertical load

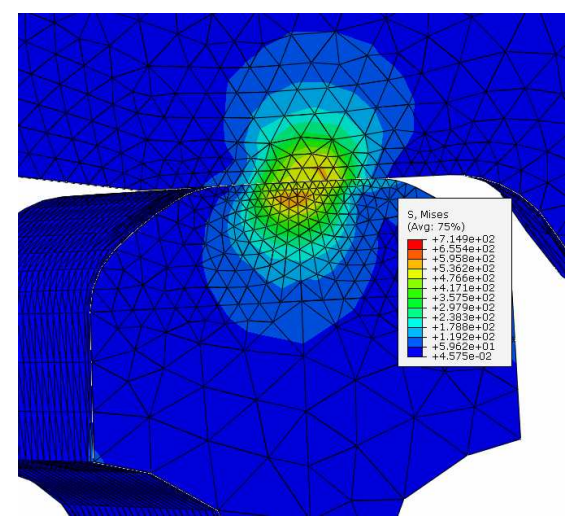

(b) Vertical and lateral load

Figure 12. von Mises stress distribution, $K_{x}=K_{y}=1000 \mathrm{~N} / \mathrm{mm}, K_{z}=10000 \mathrm{~N} / \mathrm{mm}, \mu=0.31$.

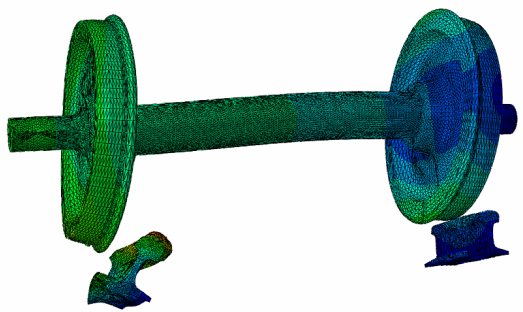

(a) $115 \mathrm{~Hz}$

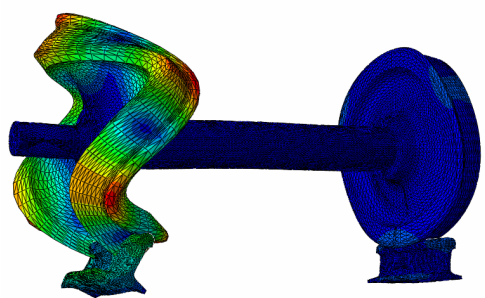

(b) $1279 \mathrm{~Hz}$

Figure 13. Flutter instability, $K_{x}=K_{y}=1000 \mathrm{~N} / \mathrm{mm}, K_{z}=10000 \mathrm{~N} / \mathrm{mm}, \mu=0.31$.

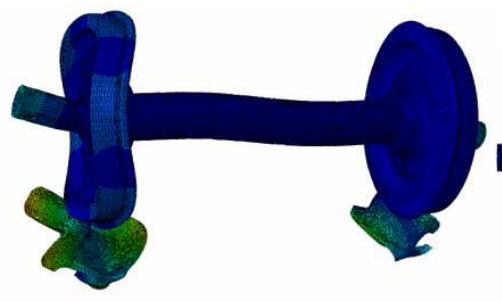

(a) $1197 \mathrm{~Hz}$

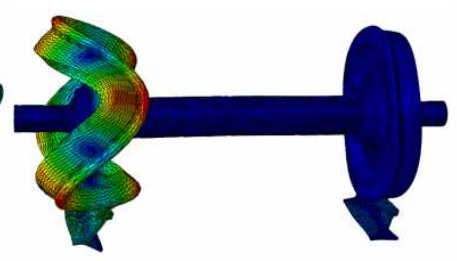

(b) $1278 \mathrm{~Hz}$

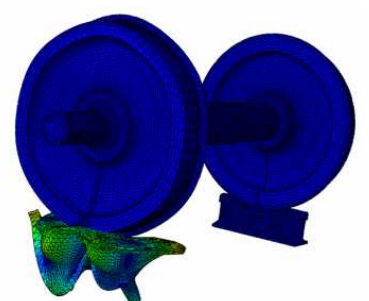

(c) $5520 \mathrm{~Hz}$

Figure 14. Flutter instability, $K_{x}=K_{y}=1000 \mathrm{~N} / \mathrm{mm}, K_{z}=10000 \mathrm{~N} / \mathrm{mm}, \mu=0.47$. 


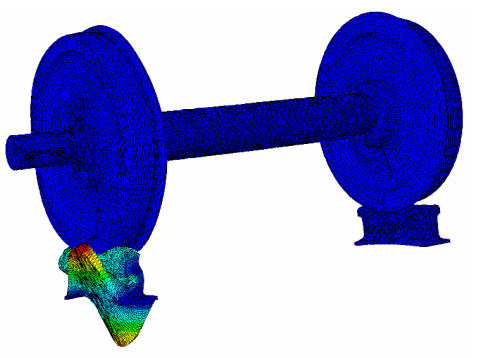

(a) $2217 \mathrm{~Hz}$

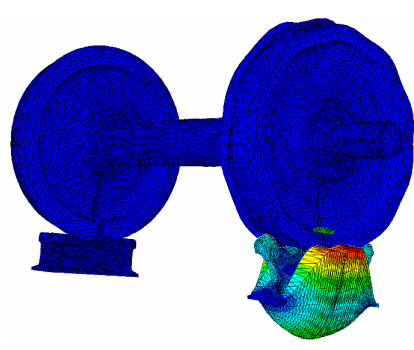

(b) $10675 \mathrm{~Hz}$

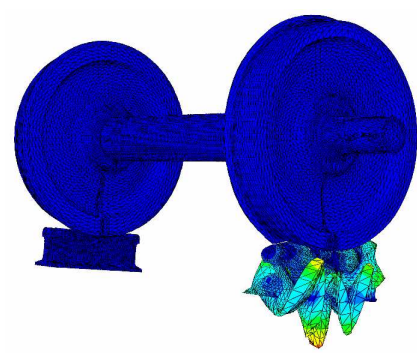

(c) 11603

Figure 15. Flutter instability, $K_{x}=K_{y}=10^{4} \mathrm{~N} / \mathrm{mm}, K_{z}=10^{8} \mathrm{~N} / \mathrm{mm}, \mu=0.33,0.35$.

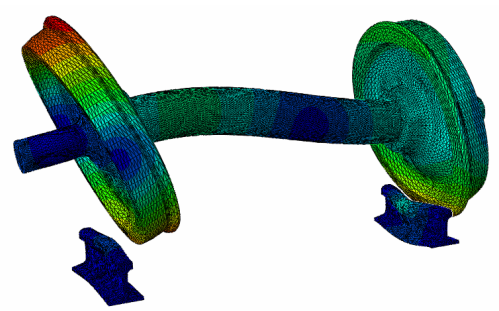

(a) $217 \mathrm{~Hz}$

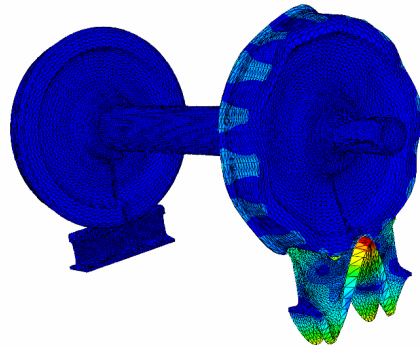

(b) $6916 \mathrm{~Hz}$

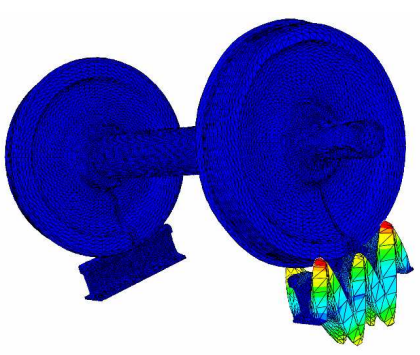

(c) $9396 \mathrm{~Hz}$

Figure 16. Flutter instability, $K_{x}=K_{y}=K_{z}=10^{8} \mathrm{~N} / \mathrm{mm}, \mu=0.31,0.35$.

The results obtained under various conditions are summarized in Table 2. It was found that rail supporting stiffness, axle load, and friction coefficient influenced the instability of the wheel/rail system. The decrease of the vertical load from 12000 to 10000 Kgf generated two new instable modes. When $K_{x}=K_{y}=1000, K_{z}=10000 \mathrm{~N} / \mathrm{mm}$, and $\mu=0.35$, four instable modes were generated. But the wheelset moved to the positive Y-direction by $8 \mathrm{~mm}$, all instable modes disappeared. For all boundary and loading conditions considered, when the friction coefficient was less than 0.1 , instable modes did not occur.

4.2 Squeal by longitudinal creepage: The finite element model is the same as that in 3.2. Figure 17 shows the contact stress distribution when the spring constants on the rail are $K_{x}=K_{y}=10^{5}, K_{z}=10^{8} \mathrm{~N} / \mathrm{mm}$, and the vertical wheel load was $6000 \mathrm{Kgf}$. The friction coefficient between the wheel and rail is $\mu=0.35$. Figure 17 (a) is the von-Mises stress in the contact area of the wheel under the vertical load only (the aforementioned analysis step 1). It is found the stress distribution is very similar to that of a classical Hertzian contact of two objects. Figure 17(b) shows the von-Mises stress after the frictional force by longitudinal slippage was additionally applied (analysis step 2). To simulate the longitudinal creepage, pseudo-movement of all the nodes of the rail to the longitudinal direction was given at the speed of $5 \mathrm{~m} / \mathrm{s}$. Figure 18 shows the instable modal shapes. Two instable modes occurred at frequencies 3028, and $12402 \mathrm{~Hz}$. Figure 19 is the results when $\mu=0.33$ or 0.34 and the same spring constants used in Figure 18 were applied. In this case two instable modes occurred at 3028, and $12402 \mathrm{~Hz}$. Figure 20 is the results when $K_{x}=K_{y}=10^{3}, K_{z}=10^{4}$. Two instable modes occurred at 3027 and $6431 \mathrm{~Hz}$.

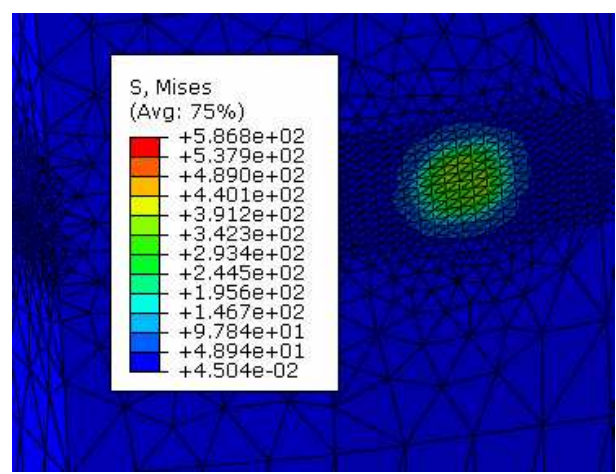

(a) Vertical load

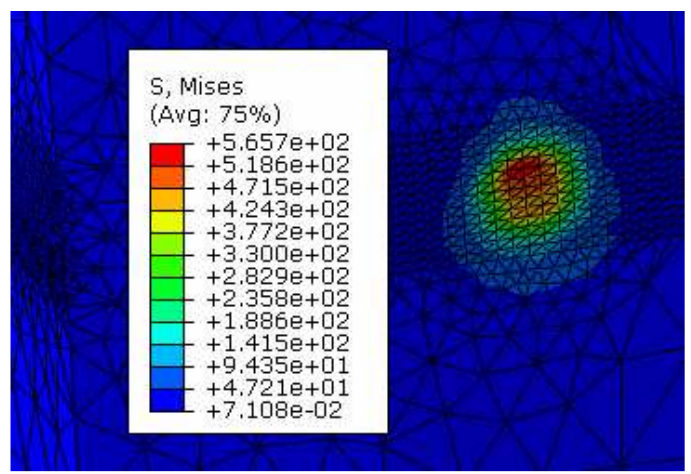

(b) Vertical load and longitudinal creepage

Figure 17. von Misess stress distribution, $\mu=0.35, K_{x}=K_{y}=10^{5}, K_{z}=10^{8}$. 


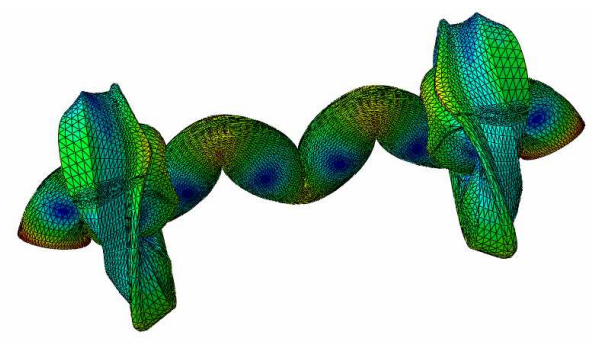

(a) $3028 \mathrm{~Hz}$

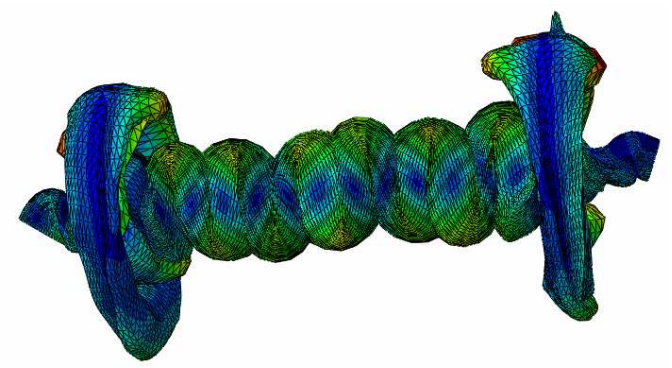

(b) $12402 \mathrm{~Hz}$

Figure 18. Flutter instability, $\mu=0.35, K_{x}=K_{y}=10^{5}, K_{z}=10^{8}$.

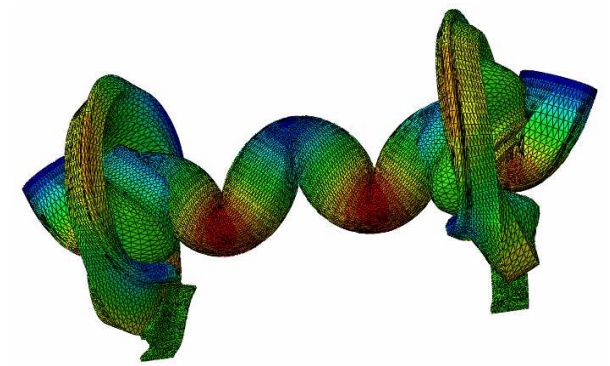

(a) $3028 \mathrm{~Hz}$

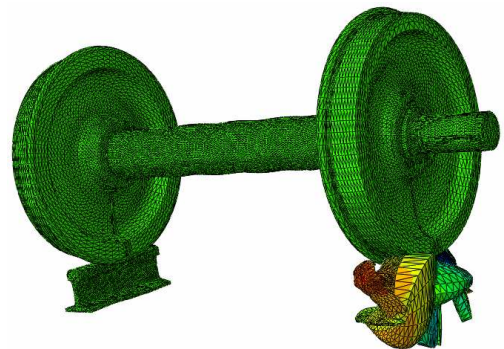

(b) $12402 \mathrm{~Hz}$

Figure 19. Flutter instability, $\mu=0.33,0.34, K_{x}=K_{y}=10^{5}, K_{z}=10^{8}$.

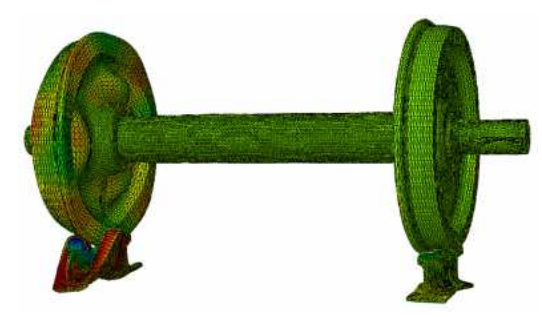

(a) $3027 \mathrm{~Hz}$

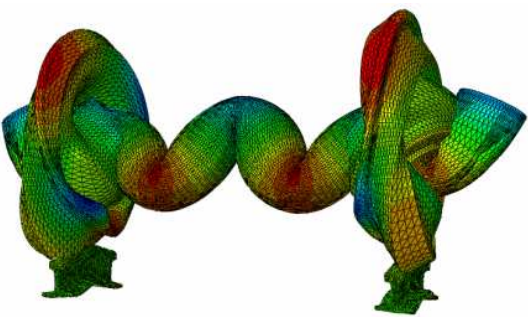

(b) $6431 \mathrm{~Hz}$

Figure 20. Flutter instability, $\mu=0.35, K_{x}=K_{y}=10^{3}, K_{z}=10^{4}$.

When the friction coefficient was less than 0.19 , instable modes did not occur. The predicted instable modal shapes are different from those in lateral creepage. They were not observed in the field test results. The conditions used for the analysis may occur when braking is applied. Flutter instabilities under various conditions were summarized in Table 2.

Table 2. Flutter instability under various conditions.

\begin{tabular}{|c|c|c|c|c|}
\hline $\begin{array}{c}\boldsymbol{K}_{\mathbf{z}}=\boldsymbol{K}_{\boldsymbol{y}} \\
(\mathbf{N} / \mathbf{m m})\end{array}$ & $\begin{array}{c}\boldsymbol{K}_{\boldsymbol{z}} \\
(\mathbf{N} / \mathbf{m m})\end{array}$ & Friction coefficient & $\begin{array}{c}\text { Vertical } \\
\text { axial load } \\
\left(\mathrm{Kg}_{\mathrm{f}}\right)\end{array}$ & $\begin{array}{c}\text { Instable modal frequency } \\
(\mathrm{Hz})\end{array}$ \\
\hline $10^{3}$ & $10^{4}$ & 0.09 & 12000 & None \\
\hline $10^{3}$ & $10^{4}$ & 0.10 & 12000 & 1280 \\
\hline $10^{3}$ & $10^{4}$ & 0.20 & 12000 & 1277 \\
\hline $10^{3}$ & $10^{4}$ & 0.31 & 12000 & 116,1279 \\
\hline $10^{3}$ & $10^{4}$ & 0.33 & 12000 & 115,1278 \\
\hline $10^{3}$ & $10^{4}$ & 0.35 & 12000 & 115,1278 \\
\hline $10^{3}$ & $10^{4}$ & 0.36 & 12000 & 115,1278 \\
\hline $10^{3}$ & $10^{4}$ & 0.37 & 12000 & 115,1278 \\
\hline $10^{3}$ & $10^{4}$ & 0.39 & 12000 & 114,1278 \\
\hline $10^{3}$ & $10^{4}$ & 0.40 & 12000 & \\
\hline
\end{tabular}


Table 2 (cont'd). Flutter instability under various conditions.

\begin{tabular}{|c|c|c|c|c|}
\hline $\begin{array}{c}K_{\mathrm{s}}=K_{y} \\
(\mathrm{~N} / \mathrm{mm})\end{array}$ & $\begin{array}{c}K_{z} \\
(\mathrm{~N} / \mathrm{mm})\end{array}$ & Friction coefficient & $\begin{array}{l}\text { Vertical } \\
\text { axial load } \\
\left(\mathrm{Kg}_{\mathrm{f}}\right)\end{array}$ & $\begin{array}{l}\text { Instable modal frequency } \\
(\mathrm{Hz})\end{array}$ \\
\hline $10^{3}$ & $10^{4}$ & 0.42 & 12000 & $114,1196,1278$ \\
\hline $10^{3}$ & $10^{4}$ & 0.43 & 12000 & $114,1196,1278$ \\
\hline $10^{3}$ & $10^{4}$ & 0.45 & 12000 & $114,1197,1279$ \\
\hline $10^{3}$ & $10^{4}$ & 0.47 & 12000 & $113,1197,1278,5520$ \\
\hline $10^{3}$ & $10^{4}$ & 0.35 & 10000 & $114,1192,1272,6423$ \\
\hline $10^{3}$ & $10^{4}$ & 0.35 & 14000 & 116,1284 \\
\hline $10^{3}$ & $10^{4}$ & 0.35 & 12000 & 116,1278 , wheelset moved to Y-direction by $5 \mathrm{~mm}$ \\
\hline $10^{3}$ & $10^{4}$ & 0.31 & 12000 & 117,1278 , wheelset moved to Y-direction by $5 \mathrm{~mm}$ \\
\hline $10^{3}$ & $10^{4}$ & 0.35 & 12000 & None, wheelset moved to Y-direction by $8 \mathrm{~mm}$ \\
\hline $10^{4}$ & $10^{8}$ & $0.10,0.11,0.12,0.13$ & 12000 & None \\
\hline $10^{4}$ & $10^{8}$ & 0.31 & 12000 & $211,2216,11603$ \\
\hline $10^{4}$ & $10^{8}$ & $0.33,0.35$ & 12000 & $214,2217,10675,11603$ \\
\hline $10^{4}$ & $10^{8}$ & 0.37 & 12000 & $213,136,2217,10675,11603$ \\
\hline $5 \times 10^{4}$ & $10^{8}$ & 0.35 & 12000 & 214 \\
\hline $10^{5}$ & $10^{7}$ & 0.35 & 12000 & 215,9403 \\
\hline $10^{5}$ & $10^{8}$ & 0.35 & 12000 & 215 \\
\hline $10^{8}$ & $10^{8}$ & $0.31,0.35$ & 12000 & $217,6916,9396$ \\
\hline $10^{8}$ & $10^{8}$ & $0.16,0.17$ & 12000 & 6916 \\
\hline $10^{8}$ & $10^{8}$ & $0.10,0.12,0.13,0.15$ & 12000 & None \\
\hline
\end{tabular}

\section{Conclusions}

In this study, the wheel/rail instability produced by lateral and longitudinal creepage was successfully simulated by the complex eigenvalue approach. It was found that rail supporting stiffness, axle load, and friction coefficient influenced the instability of the wheel/rail system. For all boundary and loading conditions considered, when the friction coefficient was less than 0.1 , instable modes did not occur. The first natural mode was the bending mode of the wheel, and natural modal shapes at higher frequencies were the combination of wheel and rail deformations. The predicted instable modes in lateral creepage could explain the field test results. It was also found that longitudinal creepage could generate instable modes, but the modal shapes were different from those in lateral creepage. The developed approach can easily predict instable vibration modes and be applicable to the design of a wheel/rail system in which squeal does not occur. One of the limitations of this study comes from the assumptions used in modeling the real long rail as a short equivalent rail in terms of stiffness. To more correctly simulate the instability of wheel/rail produced by creepage, it seems that the vibrational behaviour of the rails installed in track should be studied and imported into the modelling.

\section{Acknowledgement}

This research was supported by a grant (13-RTRP-B072484-01) from the Railroad Technology Research Program funded by Ministry of Land, Infrastructure and Transport of Korean government.

\section{References}

ABAQUS Analysis User's manual, Ver. 6.5, Vol. II. 6.3.6.

Goo B.C. 2014. Finite element analysis of wheel/rail squeal noise, WIT Transactions on the Built Environment, Vol. 135, pp. 217225.

Brunel J.F., Dufrenoy P., Nait M., Munoz J.L. and Demilly F. 2006. Transient models for curve squeal noise. Journal of Sound and Vibration, Vol. 293, pp. 758-763.

Chen G.X., Xiao J.B., Liu Q.Y., Zhou Z.R. 2008. Complex eigenvalue analysis of railway curve squeal. Noise and Vibration Mitigation 2008; NNFM99, pp. 433-439.

Brizard D., Chiello O., Sinou J.J. and Lorang X. 2011, Performance of some reduced bases for the stability analysis of a disc/pads system in sliding contact. Journal of Sound and Vibration, Vol. 293, pp. 735-746.

de Beer F.G., Janssens M.H.A. and Kooijman P.P. 2003. Squeal noise of rail-bound vehicles influenced by lateral contact position. Journal of Sound and Vibration, Vol. 267, pp. 497-507.

Eriksson M. and Jacobson S. 2001. Friction behaviour and squeal generation of disc brakes at low speeds. Proceedings of the Institution of Mechanical Engineers D 215, Vol. 12, pp. 1245-1256. 
Festjens H., Gaël C., Franck R., Jean-Luc D. and Remy L. 2012. Effectiveness of multilayer viscoelastic insulators to prevent occurrences of brake squeal: A numerical study, Applied Acoustics, Vol. 73, No. 11, pp. 1121-1128.

Glocker Ch., Cataldi-Spinola E. and Leine R.I. 2009. Curve squealing of trains: Measurement, modelling and simulation. Journal of Sound and Vibration, Vol. 324, pp. 365-386.

Heckl M.A. and Abrahams I.D. 2000. Curve squeal of train wheels, part 1: mathematical model. J. of Sound and Vibration; Vol. 229, No. 3, pp. 669-693.

Heckl M.A. 2000. Curve squeal of train wheels, part 2: which wheel modes are prone to squeal? J. of Sound and Vibration; Vol. 229, No. 3, pp. 695-707.

Heckl M.A. and Huang X.Y. 2000. Curve squeal of train wheels, part 3: active control. J. of Sound and Vibration, Vol. 229, No. 3, pp. 709-735.

Hsu S.S., Huang Z., Iwnickl, S.D., Thompson D.J., Jones C.J.C., Xie G. and Allen P.D. 2007. Experimental and theoretical investigation of railway wheel squeal. Proc. IMechE Part F: J. Rail and Rapid Transit, Special Issue Paper, pp. 59-73.

Kang J. 2012. Finite element modelling for the investigation of in-plane modes and damping shims in disc brake squeal, Journal of Sound and Vibration, Vol. 331, No. 9, pp.2190-2202.

Kinkaid N.M., O'Reilly O.M. and Papadopoulos P. 2003. Automotive disc brake squeal. Journal of Sound and Vibration, Vol. 267, No. 1, pp. 105-166.

Liu P., Zheng H., Cai C., Wang Y.Y., Lu C., Ang K.H. and Liu G.R. 2006. Analysis of disc brake squeal using the complex eigenvalue method. Applied Acoustics, Vol. 68, pp. 603-615.

Liu X. and Meehan P.A. 2013. Investigation of the effect of lateral adhesion and rolling speed on wheel squeal noise. Proc IMechE Part F: J Rail and Rapid Transit, Vol. 227, No. 5, pp. 469-480.

Monk-Steel A.D., Thompson D.J., de Beer F.G. and Janssens M.H.A. 2006. An investigation into the influence of longitudinal creepage on railway squeal noise due to lateral creepage, Journal of Sound and Vibration, Vol. 293, No. 766-776.

Rhee S.K., Tsang P.H.S. and Wang Y.S. 1989. Friction-induced noise and vibration of disc brakes. Wear, Vol. 133, pp. 39-45.

Sinou J.-J., Loyer A., Chiello O., Mogenier G., Lorang X., Cocheteau F. and Bellaj S. 2013. A global strategy based on experiments and simulations for squeal prediction on industrial railway brakes. Journal of Sound and Vibration, Vol. 332, No. 20, pp. 5068-5085.

\section{Biographical notes}

B. C. Goo received Ph.D. from the Uni. of Franche-Comté, France in 1995. He has been a principal researcher in the New Transportation Department, Korea Railroad Research Instituter since 1996, Korea. His research interests include brake system, brake squeal noise, structural analysis, wheel/rail contact, fatigue, shape memory alloys, etc.

J. C. Kim received Ph.D. from the Uni. of Tokyo, Japan in 1996. He is a principal researcher in the High Speed Train Department, Korea Railroad Research Instituter. His main research areas include noise, vibration, signal processing, etc.

Received November 2015

Accepted December 2015

Final acceptance in revised form December 2015 